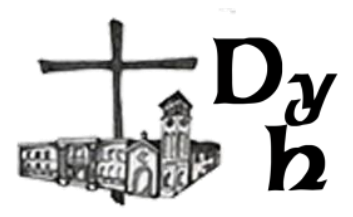

Encuentros y desencuentros en torno a la Educación Sexual Integral

Ana Perelman | Cristián Expósito

Dios y el hombre, vol. 5, n. 1, e072, 2021

ISSN 2618-2858 - https://doi.org/10.24215/26182858e072

https://revistas.unlp.edu.ar/DyH/index

Cátedra libre de pensamiento cristiano - UNLP

Seminario Mayor San José

La Plata, Buenos Aires, Argentina

\title{
ENCUENTROS Y DESENCUENTROS EN TORNO A LA EDUCACIÓN SEXUAL INTEGRAL
}

\author{
Encounters and Disagreements around Comprehensive Sexual Education
}

\section{Ana Perelman | Cristián Expósito}

perelman.ana@gmail.com | cdexposito@uda.edu.ar

Universidad del Aconcagua | Centro de Investigaciones Cuyo/CONICET

Mendoza - Argentina

\begin{abstract}
Resumen
Este artículo tiene por objeto poner de relieve la Ley Nacional de Educación Sexual Integral № 26150 con 15 años de vigencia en Argentina, pero con una reciente aplicación real en las escuelas del país. No obstante, resulta necesario realizar una lectura atenta de sus artículos y de los lineamientos curriculares a fin de ubicar y explicar algunos supuestos (principalmente su vinculación a la «perspectiva de género») en relación con el espíritu de la ley. En este sentido, se analiza de manera interpretativa -desde la razonabilidad de la norma- el contexto histórico que la antecede y la propicia, sus verdaderos alcances y objetivos, como así también los debates y críticas en torno a su vigencia y aplicación. De este modo se aspira a dilucidar malos entendidos y disolver inquietudes en relación a la aplicación de la Ley de Educación Sexual Integral (ESI).
\end{abstract}

Palabras claves: ley de educación sexual; perspectiva de género; lineamiento curricular; educación.

\section{Abstract}

This article aims to highlight the National Law of Comprehensive Sexual Education No. 26150 with 15 years of validity in Argentina, but with a recent real application in the country's schools. However, it is necessary to carefully read their articles and the curricular guidelines in order to locate and explain some assumptions (mainly their link to the "gender perspective") in relation to the spirit of the law. In this sense, it is analyzed in an interpretive way -taking as a starting point the reasonableness of the norm- the historical context that precedes it and favors it, its true scope and objectives, as well as the debates and criticisms regarding its validity and application. In this way, it aims to clarify misunderstandings and dissolve concerns in relation to the application of the Comprehensive Sex Education Law (ESI).

Key words: sexual education law; gender perspective; curricular guidelines; education.

Recibido: 21/01/2021

Aceptado: 13/05/2021

Publicado: 12/07/2021 


\section{Introducción}

Juan Carlos Tedesco (2001) sostiene que es muy difícil implementar, de forma eficaz, cambios en la educación argentina. Esta afirmación quedó ampliamente demostrada ante la variedad de encuentros y desencuentros generados frente a la sanción e implementación de la Ley Nacional de Educación Sexual Integral (ESI) No 26150 (2006). La ESI generó encendidos debates y construcción de consensos tanto en el Parlamento Nacional, como en el ámbito mediático y de la opinión pública (Esquivel, 2013).

Dado el impacto social y educativo que trajo aparejado esta ley, el presente estudio propone analizarla exhaustivamente para desestimar algunos supuestos que podrían obstaculizar su comprensión cabal. Para ello, se recurrirá a caracterizar el contexto histórico que la antecede y propicia, definir los alcances y objetivos de la Ley de Educación Sexual Integral y exponer distintas miradas críticas y favorables sobre la misma.

\section{Evolución histórica, rumbo a la Educación Sexual Integral}

Las autoras Marcela País Andrade y Camila Suarez (2019) en una publicación sobre el abordaje crítico de la ley de educación sexual integral (ESI), realizaron una línea de tiempo a modo de cuadro que revela los procesos de negociación y resistencia en torno a la sexualidad en políticas públicas argentinas. Remarcan que en los '60 comienza la difusión de los nuevos métodos anticonceptivos y la atención ginecológica como novedad del momento, la cual era impulsada por profesionales de la medicina. En 1974, el entonces presidente Juan Domingo Perón, sanciona un decreto que establece control estricto por parte del Estado en relación con la compra-venta de medicamentos anticonceptivos (Decreto $N^{0} 659$, 1974). Asimismo, continúa dicha restricción a cargo del Gobierno de Facto (1976-1983) a través del Decreto No 3938 (1978) presentado por la Comisión Nacional de Políticas Demográficas. Rearte, et al. (2016) sostienen que "ambos decretos tienen objetivos complementarios, el primero regido por los objetivos de poblar para gobernar y el segundo sostenido en razones de seguridad nacional en el que se advierte la necesidad de poblar la frontera" (p. 3). 


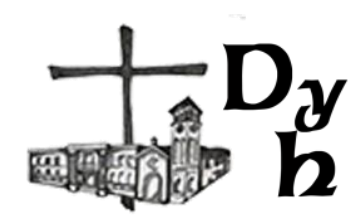

El 18 de diciembre de 1979, la Asamblea de las Naciones Unidas (ONU, 1979) adopta el tratado internacional de la Convención sobre la Eliminación de todas las Formas de Discriminación contra la Mujer (CEDAW), suscrita por Argentina en julio de 1980 y es ratificada como Ley No 23179 en 1985. En el 2006, el Congreso Nacional acepta y aprueba el protocolo facultativo que garantiza los derechos de las mujeres y exige a los Estados miembros la creación de instrumentos y políticas públicas que permitan su cumplimiento en igualdad de condiciones respecto de los hombres (Ley 26171, 2006).

En la década del 80 se lleva a cabo el II Congreso Pedagógico Nacional (1984) donde se plantea la necesidad de estudiar y dilucidar los diversos problemas, dificultades, limitaciones y defectos que enfrentaba la educación (Ley 23114, 1984, art 2, inc. c). En ese mismo año, se dicta el primer curso de educación sexual en una escuela de educación superior docente, en la ciudad de Buenos Aires mediante Ordenanza No40089 (1984). Desde la década del 80, se viene constituyendo un marco jurídico impulsado por las luchas del movimiento feminista y movimientos sociales en pro de la diversidad, marcando un paulatino avance en las políticas de regulación de la sexualidad (Boccardi, 2008).

En 1989 se implementa el Programa de Salud Escolar de Buenos Aires, donde se incorpora la Educación Sexual (País Andrade y Suarez, 2019). Este programa es uno de los primeros antecedentes de la Ley No 26150 (2006). En noviembre de este año, las Naciones Unidas avanzan con la "Convención sobre los derechos del niño" destacándose de ella que la franja etaria que involucre a la niñez será desde el nacimiento hasta los 18 años (ONU, 1989).

Juan Cruz Esquivel (2019) plantea que por esta época surge:

el VIH-Sida y la propagación de otras enfermedades de transmisión sexual, la iniciación sexual más temprana, el aumento del embarazo no deseado en adolescentes y la deserción escolar por esa causa, el crecimiento de casos de aborto, mortalidad materna, violencia familiar y abuso sexual, dan cuenta de un núcleo de problemáticas que lejos de situarse exclusivamente en el plano de la intimidad y en el mundo de lo privado, ocupa un lugar gravitante en el ámbito público. (p. 142) 
En 1990 se sanciona la Ley Nacional No 23798 (1990) y su Decreto Reglamentario No 1244 (1991) destinada a la lucha contra el Síndrome de Inmunodeficiencia Adquirida (SIDA). Si bien la ley de ESI se sancionaría 17 años más tarde, este marco contextual y normativo pone a la Educación Sexual como una temática relevante desde la prevención de riesgos, sin avanzar en materia de igualdad, diversidad, etc. (Cerro, 2015).

Es importante destacar que durante la década del 90 ocurren dos eventos significativos relacionados a la Educación Sexual. El primero, es la entrada en vigencia de la Convención Sobre los Derechos del Niño en la Argentina, bajo la Ley No 23849 (1990). En ella, se expresa la protección de cada niño frente al abuso sexual (Art. 19). En segundo lugar, la participación de Argentina en la Conferencia Mundial de la Mujer (ONU, 1995) de Beijing donde se proclama la igualdad de derechos y oportunidades entre hombres y mujeres.

El siguiente hecho destacable es en el año 2000, cuando la Legislatura Porteña sanciona la Ley No418 de Salud Reproductiva y Procreación Responsable. El dictamen fue aprobado contando con el apoyo de iglesias y organizaciones ecuménicas (País Andrade y Suarez, 2019). Éste fue también un importante antecedente para la ESI, al igual que la sanción de la Ley Nacional de Salud Sexual y Reproductiva No25673 (2002) que Morgade (2011) sintetiza con las siguientes palabras: "establece que toda la población deberá tener garantizado el acceso a la información, delegando explícitamente a la comunidad educativa la tarea de formación" (p. 5).

En el año 2004, ya próximos a la fecha de sanción de la ESI, algunos legisladores porteños quisieron impulsarla en su jurisdicción. Eleonor Faur (2018) explica que la Catedral metropolitana manifestó su oposición, el entonces Cardenal Jorge Bergoglio, actual Papa Francisco, explicó que la función estatal debería ser complementaria, volcando así la responsabilidad fundamental de la educación en la familia quien será acompañada por la escuela.

Siguiendo con la cronología de hechos, en el año 2006 comienza el sinuoso camino transitado por la Ley de ESI en el Congreso argentino. Esquivel (2013) resalta que, si bien la Ley Nacional de Salud Sexual y Procreación Responsable No 25673 (2002) ya estaba sancionada, ésta "prescribía la instrucción sexual en las 


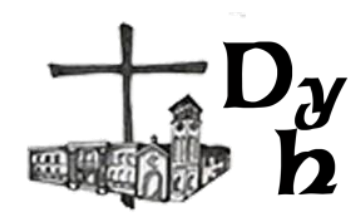

escuelas de todo el país, ante la falta de acciones en ese sentido, sectores políticos y sociales con trayectoria en derechos sexuales impulsaron la normativa específica sobre educación sexual" (p. 142). El 16 de agosto de 2006 la Cámara de Diputados dio media sanción. Por último, el Honorable Senado de la Nación Argentina sanciona la Ley de Educación Sexual Integral No 26150 el 4 de octubre de 2006.

En resumen y siguiendo las palabras de Morgade (2019) la ESI surge de una construcción inmersa en un caudal de convenciones y leyes que: "conformaron el plexo normativo de su sanción y volumen de la producción pedagógica en el campo educativo" (p. 47). Añade que los principios de los tratados de derechos humanos, han sido recogidos por la Ley de Educación Sexual Integral.

\section{Políticas culturales que acompañan a la ESI}

Es preciso aclarar qué políticas han girado en torno a esta ley, tanto antes como después de su sanción, para poder comprender la dirección que toma este Programa Nacional de ESI, contemplando los emergentes contextuales de nuestro país en ese momento histórico.

Ya por los años 60, el uso de la píldora anticonceptiva hizo una fuerte separación entre el erotismo y la reproducción. Este aspecto fue el punto de partida del modelo liberal, fuertemente cuestionado por el conservadurismo; a su vez, el mismo había sido jaqueado en los 80 y 90 por la pandemia del VIH-SIDA (Morgade, 2011). El autor norteamericano Jeffrey Weeks (1998) explica -hace 22 años atrás- cómo la existencia de mayor permisividad en cuestiones culturales y sociales, incide directamente en el modo de vivir del cuerpo sexuado. Asimismo, hace hincapié en que se ha modificado la perspectiva respecto del matrimonio tradicional, la conformación y configuración de la familia y sostiene que existe un mayor reconocimiento de las diversidades sexuales.

Este giro cultural que señala Weeks (1998), toma relevancia como política de estado en nuestro país y es acompañada con leyes como la famosa Ley No 23515 (1987) de Divorcio vincular sancionada durante el mandato del difunto presidente Raúl Alfonsín (1983-1989), la Ley No 26364 (2008) de Prevención y sanción de la 
trata de personas y asistencia a sus víctimas, la Ley No 26485 (2009) de Protección Integral a las Mujeres, la Ley No 26618 (2010) de Matrimonio Igualitario y la Ley No 26743 (2012) de Identidad de Género, entre otras.

En base a esta reconfiguración cultural, Ángela Quintero (2005), en un artículo publicado en la Revista de Trabajo Social, propone una comparación entre la familia tradicional y la familia moderna, resaltando como novedad la escasez de miembros, vínculos de pareja más inestables y el emergente de la mujer como proveedora económica. Destaca también que, en muchas familias coexisten el modelo tradicional (el padre como única autoridad y proveedor económico, la mujer atendiendo al hombre e hijos, etc.) y el nuevo modelo. También dedica un párrafo a comentar que los lazos de sangre han sufrido mutaciones; hoy en día y en términos funcionales, la consanguinidad es irrelevante y la maternidad y la paternidad son más que las relaciones netamente de sangre, acompaña este último tópico con la procreación asistida y adopción.

Frente a esta nueva realidad cultural marcada por una mayor difusión social de las relaciones sexuales prematrimoniales y la aceptación más abierta del embarazo antes o fuera del matrimonio; la escuela tuvo que reconfigurar su rol en la sociedad para adaptarse a esta nueva concepción de la vida sexual, en general, y a la expresión de afectos y deseos, en particular. Este cambio de paradigma se debe, en gran medida, al movimiento social de mujeres y movimientos sociosexuales (Morgade, 2011).

\section{¿Qué es la ESI? Alcances y objetivos.}

La Ley 26150 (2006) ESI se presenta dentro de "una tensión estructural y un desafío coyuntural" (Faur, 2018, p. 9) ya que sus objetivos atentan contra la sensibilidad de aquellos ideales conservadores; sin embargo, revisten la relevancia de velar por los derechos de los estudiantes en general:

a) Incorporar la educación sexual integral dentro de las propuestas educativas orientadas a la formación armónica, equilibrada y permanente de las personas; b) Asegurar la transmisión de conocimientos pertinentes, precisos, confiables y actualizados sobre los distintos aspectos involucrados en la educación sexual 


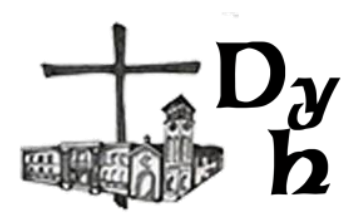

integral; c) Promover actitudes responsables ante la sexualidad; d) Prevenir los problemas relacionados con la salud en general y la salud sexual y reproductiva en particular; e) Procurar igualdad de trato y oportunidades para varones y mujeres. (Ley 26150, 2006, Art. 3)

Cada uno de los objetivos enunciados, en estrecha comparación con los de la Ley de Salud Reproductiva y Procreación Responsable No 418 (2000) y los de la Ley Nacional de Salud Sexual y Reproductiva No 25673 (2002) -mencionadas anteriormente-, permiten comprender cabalmente que "la ley en sí fue solo un punto de catalización de otras leyes anteriores, y sobre todo, un punto de partida para un despliegue y profundización posterior" (Morgade, 2019, p. 49).

\section{Definiciones en torno a la ESI}

La Ley de Educación Sexual Integral No 26150 (2006) pone un manto de garantías para el cumplimiento de los derechos de la infancia a la libertad de expresión y a la escucha por parte de las personas adultas. Esto permite el fortalecimiento de aquellas capacidades que les ayuden a asumir una vida responsable ya que, por derecho, los dota de información pertinente, objetiva y validada científicamente. Contribuye además, con la prevención de enfermedades de transmisión sexual tales como el VIH-SIDA. Esta Ley permite el acceso de la escuela en realidades que antes tenía veladas como son las situaciones de vulneración de derechos referidas a violencia, abuso, maltrato de cualquier tipo, permitiéndole tomar las medidas de protección y reparación necesarias (Morgade, 2019).

La ESI apunta a promover actitudes responsables, prevenir enfermedades y garantizar igualdad entre varones y mujeres, considerando aspectos biológicos, psicológicos, sociales, afectivos y éticos como dimensiones centrales y constitutivas de la educación sexual. Sin embargo, la modificación sustancial con respecto a lo que primaba hasta su sanción, está relacionada con que la variable sanitarista no iba a ser la única razón para incluir la ESI en las escuelas. La mirada innovadora estuvo puesta en reconocer a los niños, adolescentes y jóvenes como sujetos de 
derecho, por lo cual, tienen el derecho y la obligación de recibir Educación Sexual Integral. Esto significaría un quiebre paradigmático al modelo vertical de la patria potestad (Esquivel, 2013).

Siguiendo con este análisis descriptivo y pormenorizado de la ESI, consideramos relevante destacar el inciso ' $e$ ' del artículo 3 de la misma que sostiene: "Procurar igualdad de trato y oportunidades para varones y mujeres." (Ley 26150, 2006, Art. 3, inc. e). Este es el único punto de la ley donde se explicita la concepción de igualdad entre ambos sexos; se lo expone como algo obvio y bidireccional propiedad intrínseca a la naturaleza del hombre como a la mujer. Es aquí que surge la siguiente pregunta: ¿Dónde está el punto de inflexión que acaparó las más disidentes voces de la Argentina? Añadiendo al interrogante, se resaltará el Artículo $N^{\circ} 5$ de la Ley ESI, el cual expone claramente una temática que de haber sido comprendido en forma cabal, muchos debates se hubiesen reducido en modo considerable:

Las jurisdicciones nacionales, provincial, de la Ciudad Autónoma de Buenos Aires y municipal garantizarán la realización obligatoria, a lo largo del ciclo lectivo, de acciones educativas sistemáticas en los establecimientos escolares, para el cumplimiento del Programa Nacional de Educación Sexual Integral. Cada comunidad educativa incluirá en el proceso de elaboración de su proyecto institucional, la adaptación de las propuestas a su realidad sociocultural, en el marco del respeto a su ideario institucional y a las convicciones de sus miembros. (Ley 26150, Art. 5, 2006)

Por lo tanto, el artículo plantea que el cumplimiento del programa estará sujeto a la realidad social propia de la cultura que impere en la institución, ya sea de gestión pública o privada, contemplando y respetando el ideario institucional y las convicciones de sus miembros. Esto representa entonces un margen de maniobrabilidad para aquellas instituciones que se han pronunciado en contra del abordaje integral de la ESI, tales como la Iglesia católica que marcó especial presencia en el debate, instalándose como actor protagonista de la vida pública del país (Torres, 2016). 


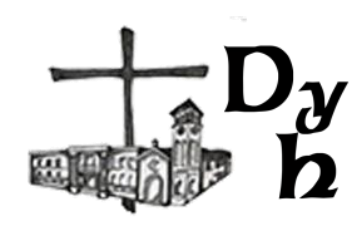

\section{Educación "Integral"}

Como plantea Esquivel (2013) la Ley Nacional de Educación Sexual Integral No 26150 (2006) no especifica un procedimiento didáctico para su enseñanza al ser sancionada; solo manifiesta la noción de «integral» que refiere a impartirla de modo transversal, cabal y acorde con la edad evolutiva del estudiante. Esto abre la posibilidad de integrar la Educación Sexual a la disciplina de estudio, cualquiera sea la asignatura, área o experiencia que se proponga en el aula. Sabrina Orden (2016) junto con sus colegas ponen en práctica esta transversalidad y concluyen que el tratamiento del contenido del área disciplinar al igual que el abordaje de la Educación Sexual Integral no fue fragmentado ni aislado. Desde una noticia del diario sobre un cruel femicidio, plantearon a sus alumnos contenidos a enseñar propios del área de la Lengua Inglesa y, a su vez, "generó una fuerte convicción en la ciudadanía crítica, en la lucha por sus derechos y un compromiso ideológico con posicionamientos claros respecto al sentido público que debe tomar la violencia de género en sus vidas cotidianas" (Orden, Pichilef, y Siderac, 2016, p. 13).

Aportando al término «integral», el reconocido pedagogo y educador Juan Carlos Tedesco (2001), quien entonces era Ministro de Educación de la Nación, ha compartido su visión:

Este enfoque integral [de la sexualidad] tiene como propósito que la Educación Sexual brindada en las escuelas supere el mero estudio de la anatomía y la fisiología de la sexualidad así como cualquier otro reduccionismo, sean éstos de carácter biológico, psicológico, jurídico, filosófico, religioso o sociológico. (Res. CFE No 43 Anexo, 2008, p. 8)

\section{Conformación de lineamientos curriculares}

En el año 2007, el Ministerio de Educación convocó a la conformación de una Comisión Interdisciplinaria de Especialistas para la elaboración de los contenidos curriculares necesarios para dar cumplimiento a la Ley de Educación Sexual Integral (Res. CFE No 382, 2007). Estos especialistas representaban diversos estamentos sociales, tales como: la religión católica a través del Consejo Superior 
de Educación Católica (CONSUDEC) la cual depende de la Comisión Episcopal de Educación Católica de la Conferencia Episcopal Argentina, como así también representantes de diferentes Iglesias Evangélicas y referentes del judaísmo.

La Comisión Interdisciplinaria de Especialistas dio origen al Programa Nacional de Educación Sexual Integral en el ámbito del Ministerio de Educación, Ciencia y Tecnología (Res. CFE $N^{\circ} 45,2008$ ). Este programa plantea los lineamientos para hacer efectivo el derecho a recibir Educación Sexual Integral en todos los establecimientos educativos públicos y privados desde el Nivel Inicial hasta el Nivel Superior de Formación Docente y de Educación Técnica (Ley 26150, Art. 1). También destinan especial relevancia a contribuir, desde el propio Ministerio, a la implementación del Programa Nacional de ESI, cumplimentando exhaustivamente el Artículo 8 de dicha ley, el cual sostiene que:

Cada jurisdicción implementará el programa a través de: a) La difusión de los objetivos de la presente ley, en los distintos niveles del sistema educativo; b) El diseño de las propuestas de enseñanza, con secuencias y pautas de abordaje pedagógico, en función de la diversidad sociocultural local y de las necesidades de los grupos etarios; c) El diseño, producción o selección de los materiales didácticos que se recomiende, utilizar a nivel institucional; d) El seguimiento, supervisión y evaluación del desarrollo de las actividades obligatorias realizadas; e) Los programas de capacitación permanente y gratuita de los educadores en el marco de la formación docente continua; f) La inclusión de los contenidos y didáctica de la educación sexual integral en los programas de formación de educadores. (Ley 26150, Art. 8, 2006)

Continuando cronológicamente con el devenir de esta ley, en mayo de 2008 el Consejo Federal de Educación, mediante una resolución (Res. CFE 45, 2008), vota los lineamientos curriculares para la Educación Sexual Integral con propósitos formativos.

Dichos lineamientos aspiran a que los sujetos puedan desarrollarse plenamente respetando las subjetividades de los demás, coadyuvando a una sana convivencia, como así también encontrar espacio para la libertad de expresión en 


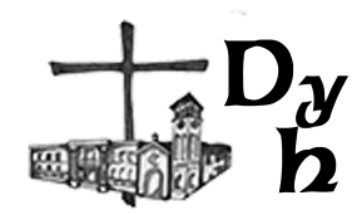

torno a la sexualidad. También se considera importante brindar información específica desde la óptica anatómica y fisiológica de la sexualidad. Además, menciona la relevancia de promover los cuidados de la salud del cuerpo y respetar las diferencias que cada uno pueda tener, de igual modo con la intimidad. Este tópico también plantea propiciar distintos aprendizajes, previniendo la vulneración de derechos: maltrato infantil, trata de personas, abuso sexual, etc. Por último, se hace mención a brindar un espacio para la verbalización de sentimientos y resolución de conflictos a través de la palabra (Res. CFE N 45. Anexo, 2008).

En el año 2008, el Programa Nacional de la Educación Sexual Integral lanzó cursos de formación docente y producción de material sobre el tema para comenzar a capacitar a los docentes. Sin embargo, Eleonor Faur, (2018) explica que la implementación del Programa se aceleró en 2009, fecha en la cual asumió como Ministro de Educación Alberto Sileoni (histórico impulsor de la ESI) lo que generó agitados debates en torno a su abordaje.

\section{Debates y críticas en torno a la ley}

Hasta aquí, se han puesto de manifiesto los objetivos de la Ley № 26150 (2006) de Educación Sexual Integral y los lineamientos curriculares que el Consejo Federal de Educación (Res. CFE No 45. Anexo, 2008) ha delimitado; sin embargo, no se han encontrado elementos en el texto de las normativas y programas que relacionen a la «Educación Sexual Integral» con la «Perspectiva de Género».

El Presbítero Guillermo Marcó (12 de agosto de 2009) explica en un suplemento del diario Clarín, que Dios creó al hombre y a la mujer y que la «ideología de género» -tal como la denominan quienes no comulgan con la «perspectiva de género»- promueve la idea de reemplazar este principio divino del sexo «hombre y mujer» por el género, el cual puede ser autopercibido. Lo conceptualiza en términos de que el género es un peligro a ser combatido, "Según esta teoría, la sexualidad no es una realidad biológica, psicológica, afectiva y espiritual, sino una construcción histórica y socio cultural." (p. 8). Afirmando que cuando esta ideología es llevada al ámbito educativo, las familias ya no tienen un hijo varón o mujer, porque lo que se pretende es que sus hijos realicen una 


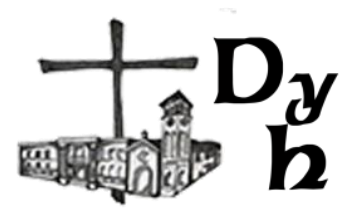

DIOS Y EL HOMBRE

búsqueda personal de la identidad sexual. También asegura que se les enseñará a los niños a elegir su género, independientemente de su sexo biológico, ya que la ideología de género afirma que el comportamiento femenino y masculino es sólo una imposición de los padres y de la cultura, y que cada cual puede elegir libremente: hombre, mujer, homosexual, bisexual, lesbiana (Marcó, 12 de agosto de 2009)

En contraposición, Boccardi (2008) menciona que el concepto de género no debe sustituir al concepto de sexo biológico; además, lejos está de incluir la idea de homosexualidad, bisexualidad o travestismo. La perspectiva de género debe ser comprendida desde la óptica de igualdad entre varones y mujeres.

El Papa Francisco ha declarado en la Conferencia Episcopal Argentina (CEA, 2018) que si bien reconoce que no hay que ignorar que se puede distinguir el sexo biológico y el papel sociocultural del sexo, no se pueden separar:

desde nuestra cosmovisión cristiana rechazamos la ideología de género, pero no podemos negar que la perspectiva de género es una categoría útil para analizar la realidad. Por ello, nos preocupa que se pretenda imponer la «ideología de género» al proyecto de educación, desconociendo la libertad que asiste a los padres y a las instituciones educativas a educar de acuerdo a sus idearios propios. (CEA, 26 de octubre de 2018)

A tal punto llega el debate, que Nicolás Márquez y Agustín Laje (2016) plantean que la ideología de género tiene como objetivo "la destrucción sexual del hombre y la mujer como productos de la heterosexualidad la cual es, curiosamente, forma de vinculación sexual que permite la conservación de nuestra especie" (p.10) En base a estos y otros motivos, en contrapartida a los lineamientos curriculares propuestos por el Ministerio de Educación, el CONSUDEC emprendió la elaboración de materiales alternativos. En concordancia con ello, argumentaban que: 


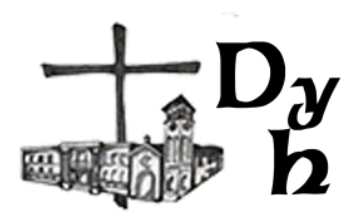

estos "cuadernos" presentados por el Ministerio de Educación de la Nación constituyen una bajada de los lineamientos curriculares a las aulas, plena de ideología de género y de conceptos que ofenden el pudor de alumnos y docentes; con un claro adoctrinamiento de los niños en torno a la confusión de los roles sexuales. (Alois, et al. 2013, p.45)

A propósito de esta postura, Laje y Márquez (2016) describen que no descreen que la cultura y la historia moldeen al ser humano, pero afirman que el hombre es naturaleza y luego cultura, en ese orden. Además, postulan que la cultura triunfa, si y solo si, no va en detrimento de la naturaleza.

Por otra parte, la tradición constructivista, desde el modelo social de las ciencias humanas, siempre se opuso a la mirada positivista de la biología y plantea que la perspectiva de género no reduce a la sexualidad a sus aspectos anatómicos y fisiológicos (Morgade, 2019). La perspectiva de género no cuestiona el orden y la función natural de los hombres y mujeres tal como sostienen aquellos sectores conservadores concibiéndola como una construcción cultural independiente del sexo, que se lo percibe como natural e invariable (País Andrade y Suárez, 2018; y Boccardi, 2008).

Palacios y Bilinkis (2013) se contraponen a los argumentos que conciben la masculinidad y la feminidad como derivadas de forma natural de características biológicas. Fundamentan que la perspectiva de género va a destacar principalmente la existencia de una lectura simbólica sobre la diferencia sexual, entendiendo que son los mecanismos sociales los que construyen las representaciones y prácticas de lo culturalmente aceptado como «femenino» y «masculino».

Como ya se ha expuesto en distintas oportunidades a lo largo del presente artículo, es recurrente encontrar que los autores relacionan (tanto a favor como en contra) la Ley de Educación Sexual Integral No26150 (2006) con la «Perspectiva/Ideología de género», dato que no se comprueba al examinar los Artículos de dicha ley y sus lineamientos curriculares diseñados en la Comisión 
Interdisciplinaria de Especialistas (Res. CFE No 382, 2007) ni por el Consejo Federal de Educación (Res. CFE No 45. Anexo, 2008). Razón por la cual consideramos irrelevante seguir sumando referentes al respecto.

\section{Conclusión}

La desinformación o exceso de noticias falsas, tal como plantea Jeanette Ivon Haneck (2020), no solo ha invadido la vida de los ciudadanos este último año de pandemia, sino que es una problemática que tiene raíces profundas en Argentina y el mundo de hoy (Luqui, 2020). Es por esta razón que la presente investigación se propuso recorrer minuciosamente y desde un contexto objetivo la Ley Nacional de Educación Sexual Integral N²6150 (2006), buscando y analizando las diferentes posturas que se han generado en torno a ella. Durante su estudio se pudo observar que en ningún momento se realiza el abordaje de la «perspectiva/ideología de género». En consecuencia, las voces protagónicas del debate -a favor y en contra- no se ajustan a los propósitos explicitados en el espíritu de la ley y en los lineamientos curriculares posteriores realizados por el Consejo Federal de Educación (Res. CFE No 43 y 45. Anexo, 2008). Estos debates tan apasionados como delicados son, en muchas ocasiones, consecuencia de la influencia de las diferentes tensiones entre posturas ideológicas cuyas apreciaciones no siempre tienen asidero en las normas sancionadas, sin embargo, reinterpretan los temas según el cristal que utilizan para ver la realidad.

Si bien, dichos debates enriquecen la pluralidad de voces y nos aproximan a un posible escenario futuro, estos temas no estuvieron contemplados por la Ley en cuestión y, consecuentemente, no se desprende de ella el abordaje de los mismos en las aulas.

El aporte que pretende brindar esta investigación radica en poder otorgar un manto de tranquilidad a la hora de abordar la Educación Sexual Integral en las escuelas, entendiéndola como una ley que, lejos de ser arbitraria, contempla la realidad cultural de cada Institución y plantea la posibilidad de educar y cuidar a los alumnos de un modo integral. 


\section{Bibliografía}

Alois, P., Galiano. A., Pastorino, E., Robledo, A., Berardo, M., Manavella, A., Rivarola, M., Basso, J. y Bustamante, A. (2014). Aportes para la implementación del programa de educación sexual integral (ESI) LEY 26.150. Versión actualizada 2014. CONSUDEC Buenos Aires: Santillana. https://consudec.org/wp/wpcontent/uploads/2019/04/Aportes-para-la-implementaci\%C3\%B3n-de-laESI-CONSUDEC.pdf

Boccardi, F. G. (2008). Educación sexual y perspectiva de género. Un análisis de los debates sobre la ley de educación sexual integral en la Argentina. Perspectivas de la Comunicación, 1(2), 48-58. http://146.83.204.140/index.php/perspectivas/article/view/35

CEA. (26 de octubre de 2018). Distingamos: Sexo, Género e Ideología. Conferencia Episcopal Argentina. https://www.episcopado.org/contenidos.php?id=1818\&tipo=unica\#ancla

Cerro, B. y. (2015). Políticas de Educación Sexual: tendencias y desafíos en el contexto latinoamericano. Revista Del IICE, (38), 7-24. https://doi.org/10.34096/riice.n38.3458

Consejo Superior de Educación Católica - CONSUDEC. Distingamos Sexo, Género e Ideología. Buenos Aires, 2018.

Decreto N03362. (1989) Programa de Salud Escolar para docentes y población escolarizada (1989) Publicado en el Boletín Oficial, 21 de diciembre de 1989. Buenos Aires, Argentina

Decreto N³938. (1978) Apruébase los objetivos y Políticas Nacionales de Población propuestos por la Comisión Nacional de Política Demográfica, enunciados en el Anexo I de este decreto, los que serán integrados en los planes nacionales. Publicado en el Boletín Oficial el 8 de febrero de 1978. https://www.boletinoficial.gob.ar/detalleAviso/primera/7075724/19780208?b usqueda $=1$

Decreto N659. (1974). Encomiéndase al Ministerio de Bienestar Social (Secretaria de Salud Publica) la realización un amplio estudio sobre aspectos demograficos. Publicado en el Boletín Oficial el 8 de marzo de 1974. 
https://www.boletinoficial.gob.ar/detalleAviso/primera/7061610/19740308?b usqueda $=1$

Del Río Fortuna, C. y. (2010). Una mirada antropológica de dos políticas públicas en sexualidad en la Ciudad de Buenos Aires. Propuesta Educativa, Facultad Latinoamericana de Ciencias Sociales Buenos Aires, (33) 95-104. https://www.redalyc.org/pdf/4030/403041789012.pdf

Esquivel, J. C. (2013). Narrativas religiosas y políticas en la disputa por la educación sexual en Argentina. Universidad Arturo Prat. Instituto de Estudios Internacionales. https://ri.conicet.gov.ar/handle/11336/3046

Faur, E. (2018). La Catedral, el Palacio, las aulas y la calle. Disputas en torno a la educación sexual integral. Revista Mora, (25), 1-10. http://revistascientificas.filo.uba.ar/index.php/mora/article/download/8534/7 437

Haneck, J. I. (2020). El Mensaje a Laodicea: un llamado oportuno en tiempos de doble pandemia. Dios y el Hombre, 4(2). https://doi.org/10.24215/26182858e065

Laje, A. \& Márquez, N. (2016). El libro negro de la nueva izquierda. Buenos Aires: Unión Editorial. Centro de Estudios LIBRE.

Ley No 23114. Congreso Pedagógico Nacional de 1984. Publicada en el Boletín Oficial, 30 de octubre de 1984. Argentina

Ley No 23179. Convención sobre la Eliminación de Todas las Formas de Discriminación contra la Mujer. Publicada en el Boletín Oficial, 3 de junio de 1985. Argentina.

Ley No 23515. De Divorcio vincular. Publicada en el Boletín Oficial, 12 de junio de 1987. Argentina.

Ley $N^{\circ}$ 23798. Ley Nacional de SIDA. Publicada en el Boletín Oficial, 14 de septiembre de 1990. Argentina.

Ley No 23849. Aprueba la Convención sobre los Derechos del Niño. Publicada en el Boletín Oficial, 27 de septiembre de 1990. Argentina.

Ley $N^{\circ}$ 25673. Ley Nacional de Salud Sexual y Reproductiva. Publicada en el Boletín Oficial, 21 de noviembre de 2002. Argentina. 
Ley No 25673. Programa Nacional de Salud Sexual y Procreación Responsable. (2002) Publicada en el Boletín Oficial, 21 de noviembre de 2002. Argentina Ley $N^{\circ}$ 26150. Ley Nacional de Educación Sexual Integral. Publicada en el Boletín Oficial, 4 de octubre de 2006. Argentina

Ley No 26171. Ratificación del protocolo del CEDAW. Publicada en el Boletín Oficial, 15 de noviembre de 2006. Argentina

Ley N²6206. Ley de Educación Nacional. Publicada en el Boletín Oficial, 28 de diciembre de 2006. Argentina

Ley $N^{\circ} 26364$. Ley de Prevención y sanción de la trata de personas y asistencia a sus víctimas. Publicada en el Boletín Oficial, 27 de diciembre de 2012. Argentina.

Ley N²6485. Ley de Protección Integral a las Mujeres. Publicada en el Boletín Oficial, 14 de abril de 2009. Argentina.

Ley $N^{\circ}$ 26618. Ley de Matrimonio Igualitario. Publicada en el Boletín Oficial, 22 de julio de 2010. Argentina.

Ley No 26743. Ley de Identidad de Género. Publicada en el Boletín Oficial, 24 de mayo de 2012. Argentina.

Ley No 418. Ley de Salud Reproductiva y Procreación Oficial. (2000) Ciudad Autónoma de Buenos Aires, Argentina.

Luqui, R. E. (2020). Declaración sobre la creación de un Observatorio de la desinformación y la violencia simbólica en medios en plataformas digitales (NODIO). Forum, (10) 253-254. https://repositorio.uca.edu.ar/handle/123456789/11094

Marcó, G. (12 de agosto de 2009). Educación, sexo y naturaleza. Valores Religiosos. Suplemento Diario Clarín. https://www.valoresreligiosos.com.ar/Archivos/Suplementos/28.pdf

Morgade, G. (2011). Toda educación es sexual. Hacia una educación sexuada justa. La Crujia.

ONU. (1979). Convención sobre la Eliminación de todas formas de Discriminación contra la Mujer. Resolución 34/180 del 18 de diciembre de 1979. https://www.ohchr.org/sp/professionalinterest/pages/cedaw.aspx 
ONU. (1989). Convención sobre los Derechos del Niño, Adoptada y abierta a la firma y ratificación por la Asamblea General en su resolución 44/25, de 20 de noviembre de 1989.

https://www.un.org/es/events/childrenday/pdf/derechos.pdf

ONU. (1995). IV Conferencia Mundial de la Mujer. Beijing, China - septiembre de 1995. Acción por la Igualdad, el Desarrollo y la Paz. https://www.unwomen.org/es/how-we-work/intergovernmentalsupport/world-conferences-on-women

Orden, S., Pichilef, A., y Siderac, S. (2016). La ESI y la desnaturalización de la violencia de género. Una experiencia en la clase de inglés. In IV Jornadas del Centro Interdisciplinario de Investigaciones en Género 13, 14 y 15 de abril de 2016 Ensenada, Argentina. Universidad Nacional de La Plata. Facultad de Humanidades y Ciencias de la Educación. Centro Interdisciplinario de Investigaciones en Género.

Ordenanza $N^{\circ} 40089$. Creación del curso de educación sexual en la escuela superior de capacitación docente. Ciclo lectivo 1985. Publicada en el Boletín Municipal, 23 de noviembre de 1984. Buenos Aires. Argentina. https://www.buenosaires.gob.ar/sites/gcaba/files/ordenanza40089.pdf

País Andrade, M. A., y Suárez, C. (2019). Disputas reales en textos distópicos ficcionales. Un abordaje crítico sobre la realidad distópica de la ley de educación sexual integral argentina. De Prácticas y Discursos: Cuadernos de Ciencias Sociales, 8(12), 173-194. http://ppct.caicyt.gov.ar/index.php/depracticasydiscursos/article/view/16671

Palacios, M. I. G., y Bilinkis, M. (2013). Juego, niñez y género en la escolarización inicial. Reflexiones a partir de la capacitación docente. Lúdicamente, 2(4). https://publicaciones.sociales.uba.ar/index.php/ludicamente/article/view/418 2

Quintero, Á. (2005). La perspectiva de género y las nuevas organizaciones familiares. Revista de Trabajo Social. Cuadernillo temático, (21). http://www.fts.uner.edu.ar/publicaciones/publicaciones/desde_el_fondo/pdf/ Nro_21/5\%20Quintero\%20Velazquez\%20\%2021.pdf 
Rearte, C., Macedo, R., y Ceballos, C. (2016). Políticas públicas subalternas en Servicios de Salud Sexual destinados a adolescentes. Margen: revista de trabajo social y ciencias sociales, (80), 13. https://www.margen.org/suscri/margen80/rearte80.pdf

Res. CFE No 382. (2007). Comisión Interdisciplinaria de Especialistas del Programa Nacional de Educación Sexual Integra. Ley Nacional № 26.150. Ministerio de Educación. Consejo Federal de Educación.

Res. CFE No 43. Anexo. (2008). Programa Nacional de Educación Sexual Integral. Ley Nacional No 26.150. Lineamientos Curriculares para la Educación Sexual Integral. Documento aprobado para la discusión. Ministerio de Educación. Consejo Federal de Educación. http://repositorio.educacion.gov.ar:8080/dspace/bitstream/handle/12345678 9/54337/lineamientos.pdf?sequence $=1$

Res. CFE N 45. (2008) Aprobación del documento "Lineamientos Curriculares para la Educación Sexual Integral. Programa Nacional de Educación Sexual Integral. Ley Nacional N²6.150". Ministerio de Educación. Consejo Federal de Educación. https://cfe.educacion.gob.ar/resoluciones/res08/45-08.pdf

Res. CFE Nº 45. Anexo. (2008). Lineamientos Curriculares para la Educación Sexual Integral. Programa Nacional de Educación Sexual Integral. Ley Nacional No 26.150. Ministerio de Educación. Consejo Federal de Educación. https://cfe.educacion.gob.ar/resoluciones/res08/45-08-anexo.pdf

Tedesco, J. C. (2001). Profesionalización y Capacitación docente. Instituto de Planeamiento de la Educación (IIPE). Buenos Aires. http://www.academia.edu/download/30428903/profesionalizacion_capacitac ion_docente.pdf

Torres, G. S. (2016). Estado, Iglesia católica y educación sexual en Argentina: una lectura desde la filosofía política. Plura. Revista de Estudos de Religião, 7(2), 248-270. https://ri.conicet.gov.ar/handle/11336/30801

Weeks, J. (1998). La invención de la sexualidad. UNAM-Paidós Ibérica. 